\title{
O ESTADO DA ARTE NA ESTIMATIVA DE BIOMASSA E CARBONO EM FORMAÇÕES FLORESTAIS
}

\author{
Péricles Silveira*, Henrique Soares Koehler**, Carlos Roberto Sanquetta***, Julio Eduardo Arce**** \\ *Eng. Florestal, M.Sc., Doutorando em Engenharia Florestal, UFPR - pericles.silveira@dprf.gov.br \\ **Eng. Florestal, Dr., Depto. de Fitotecnia, UFPR - koehler@ufpr.br \\ ***Eng. Florestal, Ph.D., Depto. de Ciências Florestais, UFPR - sanquetta@ufpr.br \\ ****Eng. Florestal, Dr., Depto. de Ciências Florestais, UFPR - jarce@ufpr.br \\ Recebido para publicação: 23/10/2006 - Aceito para publicação: 04/07/2007
}

\begin{abstract}
Resumo
O presente trabalho tem por objetivo fornecer uma visão geral do estado da arte na obtenção de estimativa de biomassa e estoque de carbono em formações florestais. Inicialmente realizou-se uma abordagem sobre o aumento da concentração de $\mathrm{CO}_{2}$ na atmosfera e a mudança ambiental global. Sobre biomassa florestal e seqüestro de carbono, foi apresentada a metodologia citada na literatura para a sua determinação e estimativa, sendo realizado um apanhado geral dos métodos diretos e indiretos e as controvérsias existentes entre eles. Seqüencialmente, fez-se uma abordagem sobre as variáveis e os modelos utilizados em estimativas de biomassa e estoque de carbono em formações florestais, como também foram relacionados alguns dos modelos mais utilizados. Realizou-se ainda um estudo comparativo entre os modelos lineares e não-lineares com relação às suas vantagens e desvantagens para estimar biomassa. Para finalizar, foram citadas as principais estatísticas utilizadas por alguns autores na comparação de modelos visando o melhor ajuste.

Palavras-chave: Métodos de estimativa de biomassa; equações alométricas de biomassa; seqüestro de carbono.
\end{abstract}

\begin{abstract}
The art state of the forest biomass estimation and carbon in forest formation. The aim of this work is to present a general view of the actual art attainment state of the forest biomass estimation and the carbon stock. Firstly, it was made an approach enquiring the $\mathrm{CO}_{2}$ concentration increase at the atmosphere and the global environment changes. Furthermore, it was presented the methodology mentioned at the literature involving the determination and estimation of the carbon and forestal biomass kidnapping, in order to write a summary of the direct and indirect methods and their controversies. Afterwards, it was made another approach considering the variables and the models used at the biomass and carbon stock at forest formations estimations, as relating other more well-known methods. In addition to that, it was organized a comparative study between the lineal and non-lineal models, considering the advantages and disadvantages of its biomass estimations. Finally, the main statistics used by some authors at the models comparison aiming the best adjustment were also cited.

Keywords: Biomass estimation method; allometric biomass equations; carbon kidnapping.
\end{abstract}

\section{INTRODUÇÃO}

Historicamente, as avaliações florestais objetivavam inventariar o potencial de uma floresta levando em consideração apenas o aspecto das reservas de madeira. A exploração da Mata Atlântica, por exemplo, vem ocorrendo desde a chegada dos portugueses ao Brasil, cujo interesse primordial era a exploração do pau-brasil. O processo de desmatamento prosseguiu com a plantação da cana-de-açúcar, a extração do ouro, a produção de carvão vegetal, a extração de madeira, a plantação de cafezais e pastagens, a produção de papel e celulose, o estabelecimento de assentamentos de colonos, a construção de rodovias e barragens e como conseqüência de um amplo e intensivo processo de urbanização, com o surgimento das maiores capitais do país, como São Paulo e Rio de Janeiro, e de diversas cidades menores e povoados (IBAMA, 2004). Segundo Higuchi et al. (2004), os inventários dos anos 60 e 70 se restringiam ao volume de madeira em tamanho comercial (normalmente considerando apenas árvores 
com DAP $>25 \mathrm{~cm}$ ), por serem exploratórios, servindo, no máximo, para estudo de viabilidade de projetos de desenvolvimento.

Estudos e análises visando não somente a preservação da biodiversidade das áreas florestais, como também relacionados ao clima, começaram a se intensificar. Segundo Campos (2001), uma das conclusões desses estudos mostra que a concentração de dióxido de carbono $\left(\mathrm{CO}_{2}\right)$ e a temperatura da atmosfera variaram conjuntamente nas últimas dezenas de milhares de anos, reforçando a preocupação de que o aumento da concentração de gases de efeito estufa na atmosfera provoque mudanças climáticas, como, por exemplo, alterando radicalmente os ciclos hidrológicos de toda uma região, intensificando e alterando a freqüência de eventos extremos (tornados, ressacas). Watzlawick (2002) afirma que está previsto um aumento de $1,5{ }^{\circ} \mathrm{C}$ a $4,5{ }^{\circ} \mathrm{C}$ até o ano 2050 , e, uma vez que a temperatura controla vários processos de crescimento e desenvolvimento das plantas, pequenas variações podem influenciar diretamente o desenvolvimento de povoamentos florestais. Segundo IPCC (2001), os impactos decorrentes dessa variação da temperatura afetarão todos os países e serão de ordem não só ambiental, mas também social e econômica.

Diante desse quadro, tem-se um consenso mundial de que estratégias devem ser estudadas e empregadas para redução da concentração de $\mathrm{CO}_{2}$ atmosférico, na tentativa de se reduzir o risco dessas alterações. Entre essas estratégias, destacam-se a redução das emissões por queima de combustíveis fósseis, a redução da queima de material vegetal e o "seqüestro" do carbono pelo plantio de florestas. Considerando que a redução da queima de combustíveis fósseis implica desaquecimento da economia de países desenvolvidos e que as mudanças no uso da terra, principalmente devido aos desmatamentos, dificilmente deixarão de ocorrer, tendo em vista ainda o crescimento da população mundial e a conseqüente necessidade de abertura de novas áreas para atividades agrícolas e de pecuária, o seqüestro de carbono por florestas torna-se uma atividade econômica atrativa, desde que ambientalmente correta, do ponto de vista do seqüestro do carbono atmosférico (SOARES; LEITE; GORGENS, 2005).

Por acumular, na estrutura carbônica das árvores, elementos poluentes nocivos à qualidade de vida, cresce a cada dia que passa o interesse pelos estudos de biomassa e conteúdo de carbono em florestas. Estas estocam carbono tanto na biomassa acima como abaixo do solo e representam mais carbono do que atualmente existe em relação ao estoque na atmosfera. Isso é justificado em função de as florestas cobrirem cerca de $30 \%$ da superfície da Terra e fixarem em torno de $85 \%$ do carbono orgânico (HOUGHTON, 1994). Para esse autor, com a perda da cobertura florestal, perde-se também a maior fonte de carbono do solo, a serapilheira e as raízes, o que, com o uso agropecuário tradicional, leva à emissão de cerca de 25 a $30 \%$ do carbono estocado em aproximadamente uma década.

Biomassa quer dizer a massa de matéria de origem biológica, viva ou morta, animal ou vegetal. O termo biomassa florestal significa toda a biomassa existente na floresta ou apenas na sua fração arbórea, e, em se tratando de biomassa de origem vegetal, vem sendo empregado o termo fitomassa (SANQUETTA, 2002). Para Alemdag (1982) ${ }^{1}$, citado por Wendling (1998), biomassa florestal é a quantidade constituída por organismos no ecossistema em termos de massa.

Trabalhos têm sido realizados utilizando-se estimativas de volume e biomassa em diferentes partes das árvores e nos compartimentos das florestas, as quais são convertidas em quantidades de carbono pela utilização de fatores de conversão, ou seja, de forma indireta (COOPER, 1983; BROWN; LUGO, 1984; BROWN; LUGO; CHAPMAN, 1986; SCHROEDER, 1992), principalmente devido ao custo elevado para obtenção desse elemento de forma direta.

Com relação a trabalhos relacionados à biomassa e carbono em que é utilizado o método direto de amostragem, podem-se citar Vogel (2006), Watzlawick (2003), Schumacher (2002), Higuchi et al. (1998).

Assim sendo, a quantificação do carbono nos ecossistemas tropicais tem recebido mais atenção (BOSCOLO; BUONGIORNO, 1997; FEARNSIDE et al., 1999; KAUFFMAN; CUMMINGS; WARD, 1994; WOOMER; PALM, 1998), pois será de grande relevância o conhecimento de carbono fixado nos ecossistemas naturais, uma vez que as florestas contribuem para a estabilidade ambiental, por exemplo, com a mitigação das temperaturas extremas, aumentando as precipitações regionais, prevenindo a erosão e deterioração do solo e tendo papel fundamental no ciclo do carbono. Constituem-se, em muitos casos,

\footnotetext{
${ }^{1}$ ALEMDAG, I. S.; STIELL, W.M. Spacing and age effects on biomass production in red pine plantations. The Forestry Chronicle, v. 5, n. 3, p. 220-224, 1982.
} 
como sumidouros, ou seja, pelo processo da fotossíntese, as florestas em crescimento absorvem $\mathrm{CO}_{2}$ da atmosfera e armazenam carbono em sua biomassa, formando grandes reservatórios desse elemento.

A quantificação de biomassa florestal, conforme Salati (1994), divide-se em métodos diretos e indiretos. Métodos diretos implicam determinações, pelo fato de as árvores serem cortadas e seus componentes separados e pesados. Nos métodos indiretos, são feitas estimativas baseadas principalmente em dados advindos dessas determinações, assim como de dados originados de inventários florestais.

O objetivo deste trabalho é fornecer uma visão geral da metodologia utilizada em estudos de determinação e estimativa de biomassa e estoque de carbono em formações florestais.

\section{Objetivos de se realizar estimativa de biomassa florestal}

Os estudos de biomassa florestal são feitos com objetivos diversos, dentre os quais destacam-se a quantificação da ciclagem de nutrientes, a quantificação para fins energéticos e como base de informação para estudos de seqüestro de carbono. Esses estudos são de grande importância para a tomada de decisões no manejo dos recursos florestais (PÁSCOA et al,. 2004). O interesse na completa utilização da árvore (raízes, tronco, ramos), o uso dos resíduos da manufatura de produtos florestais, a quantificação de material combustível em relação ao potencial de incêndio de uma floresta e outras abordagens aumentam a importância dos estudos de biomassa (HUSCH; MILLER; BEERS, 1982; PHILIP, 1994).

Para analisar as condições fitossanitárias de um ecossistema, há a necessidade de se estudarem vários fatores de forma conjunta, pois todos estão inter-relacionados. A quantificação da variável biomassa é um importante método para esse fim, pois ela é uma conseqüência direta de todos os fatores bióticos e abióticos de um ecossistema florestal (BROWN, 1997).

Guedes et al. (2001) afirmam que a biomassa $\left(\mathrm{kg} \mathrm{m}^{-2}\right)$ é um indicador de produtividade $\left(\mathrm{kg} \mathrm{m}^{-2}\right.$ $\mathrm{ano}^{-1}$ ) de um sítio, variando com a precipitação, a temperatura, a latitude e a altitude. A produtividade e a biomassa podem não ser relacionadas e variam com o estado sucessional da vegetação em causa - por exemplo, uma floresta adulta que tem muita biomassa pode ter baixa produtividade.

O volume de biomassa florestal e sua distribuição são fatores controladores do estoque de carbono global, como também servem de base para a predição futura da mudança climática (SEDJO, 1992; DIXON et al., 1994). Uma estimativa acurada da biomassa florestal e seu padrão de mudança no tempo é um pré-requisito para ajudar a entender a grande controvérsia sobre a função das florestas no ciclo do carbono (SEDJO, 1992; FAN et al., 1998; BROWN; SCHROEDER; KERN, 1999).

Visando entender como se processam as emissões de carbono na atmosfera, Salomão et al. (1996) são de opinião que é necessário que se responda a seguinte questão: qual o estoque de carbono armazenado na biomassa de uma floresta? Assim, torna-se necessário desenvolver ou utilizar metodologias que possibilitem obter estimativas da quantidade desse elemento em uma floresta, ou, mais especificamente, em diferentes partes de uma árvore. Esses autores ainda mencionam que, para se proceder à avaliação dos teores de carbono dos diferentes componentes da vegetação (parte aérea, raízes e camadas decompostas sobre o solo, entre outros) e, por conseqüência, contribuir para estudos de balanço energético e do ciclo de carbono na atmosfera, é necessário, inicialmente, quantificar a biomassa vegetal de cada componente da vegetação.

Segundo Ketterings et al. (2001), a estimativa de biomassa acima do solo é imprescindível aos estudos do balanço global de carbono. Para Higuchi et al. (1998), as estimativas de biomassa representam um importante indicador para monitorar e avaliar a exportação de nutrientes após exploração florestal, na busca de minimizar os impactos ambientais gerados por essa atividade.

\section{Determinação e estimativa de biomassa florestal}

Pela fotossíntese, as plantas capturam a energia do sol, transformando-a em energia química. Essa energia pode ser convertida em eletricidade, combustível ou calor. As fontes orgânicas que são usadas para produzir energia usando esse processo são chamadas de biomassa (BROWN, 1997).

Para Martinelli et al. (1994), biomassa é a quantidade expressa em massa do material vegetal disponível em uma floresta, sendo que os componentes de biomassa geralmente estimados são a biomassa viva horizontal acima do solo, composta de árvores e arbustos, a biomassa morta acima do solo, composta pela serapilheira e troncos caídos, e a biomassa abaixo do solo, composta pelas raízes. A biomassa total é dada pela soma de todos esses componentes.

FLORESTA, Curitiba, PR, v. 38, n. 1, jan./mar. 2008. 
Conforme Gardner; Mankin (1981), os ecossistemas florestais contêm cerca de $90 \%$ da biomassa do planeta, cobrindo aproximadamente $40 \%$ de sua superfície. A biomassa representa a matéria orgânica armazenada no ecossistema. Em função da grande proporção existente de biomassa, torna-se importante e útil o seu conhecimento para fins de avaliação dos diferentes ecossistemas (RUSSO, 1983), da ciclagem de nutrientes (GOLLEY; McGINNIS; CLEMENTS, 1971) e do armazenamento de energia solar (ANDRAE; KRAPFENBAUER, 1983), possibilitando assim a realização de avaliações e recomendações para o manejo racional dos diferentes ecossistemas.

Por serem as florestas os maiores acumuladores de biomassa do planeta, a sociedade civil organizada e a mídia vêm demandando dos profissionais que atuam na área florestal a geração de informações e conhecimentos que possam auxiliar na redução dos riscos ambientais que se colocam diante da espécie humana (SANQUETTA, 2002). Um dos aspectos mais relevantes nos estudos de fixação de carbono em florestas é a variável biomassa, a qual precisa ser determinada e estimada de forma fidedigna, caso contrário não haverá consistência na quantificação do carbono fixado nos ecossistemas florestais (SANQUETTA, 2002).

Russo (1983) relaciona seis fatores que afetam a biomassa e a produtividade: a idade do povoamento, a variabilidade genética, a nutrição, a altitude, a umidade do solo e os desbastes. O total de biomassa acima do solo também varia por região geográfica, tipo de região (úmida, encharcada ou seca), tipo florestal, estrutura florestal e grau de distúrbio da floresta (BROWN; GILLESPIE; LUGO, 1989). Segundo Spurr e Barnes (1986), existe uma relação entre biomassa e produtividade primária, conhecida como acúmulo de biomassa. Essa relação é geralmente baixa em florestas jovens de rápido crescimento, e superior onde requer mais energia para manter o alto estoque de biomassa existente.

De acordo com Curlin $(1970)^{2}$, citado por Schneider et al. (2004), geralmente a parte aérea das árvores tem sua biomassa distribuída na seguinte ordem: lenho $>$ galhos $>$ casca $>$ folhas. Para Acacia mearnsii, espécie do gênero Acacia (De Wild.), Pereira et al. (1997) constataram valores diferentes na distribuição, obtendo madeira $>$ casca $>$ galhos $>$ folhas. Essa variação pode ser atribuída a diferentes fatores, como as características da espécie e os fatores edafoclimáticos.

As metodologias usadas atualmente para se obterem estimativas de biomassa em áreas florestais são baseadas, principalmente, em dados de inventário florestal, empregando-se fatores e equações de biomassa, que transformam dados de diâmetro, altura ou volume em tais estimativas (SOMOGYI et al., 2006).

$\mathrm{Na}$ maioria dos casos, é necessária uma amostragem destrutiva para a estimativa correta de biomassa. Normalmente, a biomassa arbórea é medida a partir de seus componentes. A separação e especificação desses componentes varia de acordo com o tipo de povoamento e os objetivos a serem alcançados. Essa variação pode incluir ou excluir alguns componentes específicos, tais como flores e frutos, ou detalhar outros, como raízes e ramos, subdividindo-os em raízes finas e raízes grossas, ramos com idades e espessuras diferentes (CAMPOS, 1991).

Para Higuchi e Carvalho Júnior (1994), os estudos para quantificação de biomassa florestal dividem-se em métodos diretos (ou determinação) e métodos indiretos (ou estimativas). Determinação significa uma medição real feita diretamente na biomassa, por exemplo, a pesagem de um fuste inteiro por meio de um dinamômetro ou uma balança. Todas as árvores de uma determinada parcela são derrubadas e pesadas, sendo feita em seguida a extrapolação da avaliação amostrada para a área total de interesse. A estimativa de biomassa aérea pelo método indireto consiste em correlacioná-la com alguma variável de fácil obtenção e que não requeira a destruição do material vegetal. As estimativas podem ser feitas por meio de relações quantitativas ou matemáticas, como razões ou regressões de dados provenientes de inventários florestais (dap, altura e volume), por dados de sensoriamento remoto (imagens de satélite) e utilizando-se uma base de dados em um sistema de informação geográfica (GIS).

\section{Métodos diretos}

Os métodos diretos de amostragem de biomassa podem ser enquadrados em duas grandes categorias, segundo Sanquetta (2002): método da árvore individual e método da parcela.

\footnotetext{
${ }^{2}$ CURLIN, J. W. Nutrient cycling as a factor in site productity and forest fertilization. In: YOUNGBERRG, C. T. \& DAVEY, C. B. Ed. Tree growth and forest soil. Oregon State University Press, 1970. p. 313-326.
} 
Pardé $(1980)^{3}$, citado por Sanquetta (2002), afirma que o método da árvore individual é feito mediante a seleção de uma árvore média (mean tree method), sendo que, para se conhecer essa árvore, é preciso realizar um inventário florestal piloto e calcular o diâmetro ou a área seccional ou transversal dessa árvore. Esse autor afirma que é comum o emprego da árvore de área seccional média ou "dg". Após a definição dessa árvore, procede-se a derrubada e a determinação de biomassa de um número de indivíduos, que se constituem na amostra. Em florestas com estrutura mais complexa, geralmente é empregada uma variação desse método. Após a realização de um inventário florestal piloto para se conhecer a distribuição diamétrica da floresta, será derrubado um determinado número de árvores para cada amplitude diamétrica, abrangendo todas as classes existentes na floresta.

Segundo Higuchi; Carvalho Jr. (1994), em campo são obtidos separadamente os pesos verdes para o tronco, galhos, folhas e serragens produzidas pela divisão do tronco e galhos. Em seguida, devem-se retirar discos de aproximadamente $3 \mathrm{~cm}$ de espessura do tronco e dos galhos em alturas relativas ao comprimento total e um disco na altura do DAP. Todas as amostras do tronco, galhos grossos, galhos finos, folhas e discos devem ser colocadas em estufa até estabilizarem-se em peso, para a obtenção do peso seco.

Ogawa; Kira (1977) citam outra técnica para determinação de biomassa em árvores individuais, chamada técnica do corte estratificado (stratified clip technique), que consiste na execução do corte raso em um pequeno ponto amostral no interior da floresta a ser estudada, dividindo-se a parte de cima do solo em 10 ou mais estratos paralelos à superfície do solo. Todas as árvores dentro do ponto são cortadas em partes dentro do respectivo estrato, e as folhas, ramos e caules pertencentes a cada estrato são pesados separadamente.

O método da parcela é feito cortando-se e pesando-se toda a biomassa de uma área pré-definida, podendo ser implementado, segundo Pardé (1980) ${ }^{3}$, citado por Sanquetta (2002), pelo procedimento denominado corte total (harvest method), que consiste em se determinar toda a biomassa da floresta pelo corte e pesagem de todas as frações (inclusive as raízes) passo a passo, ou por amostragem em múltiplos estágios (multi-stage sampling), no qual cortam-se todos os indivíduos contidos na parcela, pesando-se todos os caules. Para as demais porções, são feitas determinações apenas para alguns indivíduos, estabelecendo-se uma relação de quantidades entre os dois grupos. Para Brown et al. (1989), as estimativas geradas por essas parcelas não são confiáveis, porque baseiam-se em poucas parcelas, pequenas e tendenciosamente escolhidas.

Salati (1994) afirma que são utilizadas pequenas áreas (entre 0,2 a 1,0 ha), que servem para a calibragem das equações utilizadas nas estimativas indiretas, além de permitir o conhecimento detalhado da biomassa nos diferentes compartimentos da floresta.

\section{Métodos indiretos}

Somogyi et al. (2006) afirmam que avaliações de biomassa de forma indireta podem ser feitas por dois métodos quando se trabalha em campo: uma utiliza dados de volume de árvores ou talhões e multiplica-os por um fator ou fatores apropriados, denominados fatores de biomassa (BF), que convertem (expandem ou reduzem) as estimativas de volume para estimativas de biomassa, sendo escrita da seguinte forma:

$$
B=P . B F
$$

onde: $\quad \mathrm{B}=$ biomassa em $\mathrm{kg}$ ou ton;

$\mathrm{P}=$ parâmetro de uma árvore ou talhão; por exemplo, volume em $\mathrm{m}^{3}$;

$\mathrm{BF}=$ fator apropriado da biomassa utilizado na conversão.

Outra forma de se estimar biomassa de forma indireta é realizando o ajuste de equações pelo uso de técnicas de regressão. Segundo Koehler; Watzlawick; Kirchner (2002), é o procedimento mais comum, no qual algumas árvores são amostradas, o peso de cada componente é determinado e relacionado por meio de regressão com variáveis dendrométricas, sendo escrita da seguinte forma:

$$
B=f(P 1, P 2, p 1, p 2, \ldots)
$$

onde: $\quad \mathrm{B}=$ biomassa em $\mathrm{kg}$ ou ton;

${ }^{3}$ PARDÉ, J. Forest biomass. In: Forestry Abstract Review Article. França: Station de Silviculture et de Production, Centre National de Recherches Forestieres, vol. 41. p. 349-352. 1980.

FLORESTA, Curitiba, PR, v. 38, n. 1, jan./mar. 2008. 
$\mathrm{P}=$ variáveis dendrométricas disponíveis; por exemplo, diâmetro e altura;

$\mathrm{p}=$ parâmetros do modelo.

Como a maioria dos fenômenos naturais é tipicamente não-linear, a utilização de modelos nãolineares produz estimativas mais precisas do que os lineares (SANTOS, 1996). A indicação do uso de modelos não-lineares em manejo florestal é fundamentada no crescimento de uma árvore individual e, conseqüentemente, da floresta, que apresenta uma tendência não-linear e sigmoidal, e também porque existem modelos não-lineares flexíveis e confiáveis para esse tipo de análise (REGAZZI; LEITE, 1993).

Brown (1997) afirma que o uso de equações de regressão é mais vantajoso, pois são obtidas estimativas de biomassa sem a necessidade de se calcular a variável volume, mas tendo como desvantagem o fato de que geralmente não se tem dados de todas as classes de diâmetro, uma vez que grande parte dos inventários florestais visam somente a parte comercial de uma floresta, sendo geralmente medidos os diâmetros de $10 \mathrm{~cm}$ ou mais, desprezando-se árvores menores, que podem representar até $30 \%$ da biomassa de uma floresta.

Na conversão de dados de volume em biomassa, Brown; Gillespie; Lugo (1989) afirmam que é necessária a determinação do fator de expansão (BEF), obtido pela razão da biomassa seca total acima do solo, para árvores com um DAP mínimo de $10 \mathrm{~cm}$, pela biomassa seca do volume inventariado ou comercial. Esse método é conhecido como "método BEF", segundo Fang; Wang (2001).

Fearnside (1997) afirma que, em estimativas de biomassa a partir de volume, pode ser incluída a variável densidade, chamada de "densidade básica", calculada dividindo-se a massa seca pelo volume úmido. A condição de umidade usualmente se refere à amostra de madeira imersa na água em laboratório até a saturação. Essa condição é uma aproximação das condições que a madeira apresenta quando se encontra no seu estado natural em uma floresta. Outro tipo de estimativa de biomassa derivada da aplicação de equações de regressão utiliza um conjunto de dados de diâmetro. Segundo Brown (1997), esse método basicamente envolve estimativa de biomassa por classe de diâmetro, utilizando-se o diâmetro médio por classe para representá-la e o número de árvores em cada classe. Em regiões de clima seco, esse autor recomenda que essa estimativa seja correlacionada não só com a variável diâmetro (d), mas também com a variável altura $(\mathrm{h})$.

Essa equação pode ser expressa da seguinte forma:

$$
B A=b_{0}+b 1 . h d^{2}
$$

onde: $\quad \mathrm{BA}=$ biomassa da árvore;

$\mathrm{h}=$ altura em $\mathrm{m}$;

dap = diâmetro à altura do peito em $\mathrm{cm}$;

$\mathrm{b}_{0} ; \mathrm{b}_{1}=$ coeficientes da regressão.

As técnicas de sensoriamento remoto têm sido amplamente utilizadas em estudos na área florestal, uma vez que é possível estimar parâmetros biofísicos, como biomassa, carbono e volume de madeira, pelas propriedades espectrais dos componentes da vegetação (troncos, galhos, folhas, etc.). A utilização dessa técnica em florestas heterogêneas se torna mais complexa devido à grande diversidade florística, fisionômica e fenológica que esse tipo florestal apresenta. Para as florestas implantadas, por possuírem geralmente apenas um gênero e serem inventariadas periodicamente, esse trabalho se torna mais fácil e confiável (SOUZA; PONZONI, 1998).

No emprego de um sistema de informação geográfica em estimativas de biomassa, utiliza-se geralmente uma ampla base de dados e mapas digitais de inventário, de população, clima, vegetação, solos e de topografia. Watzlawick et al. (2002) relatam que a conciliação de trabalhos de campo e dados de imagem devem ser incorporados em ambientes SIG (Sistema de Informação Geográfica), obtendo-se assim um melhor aprimoramento, visualização e maior agilização nos processos de consulta às informações, permitindo também associar essas informações a um banco de dados relacional.

Houghton (1994) salienta que nas estimativas de biomassa não se pode deixar de considerar as árvores menores, a vegetação rasteira no solo e a vegetação viva abaixo do solo (raízes), devendo-se incluir também a vegetação morta, tanto acima como abaixo do solo, em pé ou caída.

A preocupação acima referida é também considerada por Fearnside (1994), visto que a maioria dos valores publicados para biomassa muitas vezes esconde inconsistências, tais como os componentes 
subterrâneos e mortos. O autor, referenciando Brown; Gillespie; Lugo (1989), comenta que a realização de amostragens destrutivas produz valores consistentemente mais altos do que as estimativas volumétricas, visto que trabalhos realizados por muitas pessoas podem ser tendenciosos na escolha do local de estudo e serem pouco representativos, por exemplo, mais densos e menos perturbados que a média real.

Segundo Brown; Gillespie; Lugo (1989), os métodos diretos fornecem estimativas muito polêmicas, em função das estimativas estarem baseadas em dados de poucas parcelas, demasiadamente pequenas e conseqüentemente com poucas árvores grandes, além de serem freqüentemente tendenciosas na seleção. Os autores afirmam que essa tendenciosidade ocorre devido à determinação da biomassa ser trabalhosa, sendo os trabalhos extremamente pesados e monótonos, o que leva o pesquisador a escolher sempre aquilo que julga ser mais representativo, e também em função de serem poucas as chances de se repetir o trabalho, tendendo por isso a se escolher um sítio mais denso, mais homogêneo e mais fácil de trabalhar. Por essas razões, as estimativas baseadas em métodos diretos tendem, segundo esse autor, a ser sempre subestimadas. Higuchi; Carvalho Júnior (1994) e Fearnside (1991) contestam as críticas feitas por Brown, Gillespie; Lugo (1989) aos métodos diretos, ao observarem que os métodos baseados em inventários florestais são menos tendenciosos, mas suas estimativas, por outro lado, ficam muito aquém de todos os valores já obtidos por meio dos métodos diretos.

Em estudo para verificar as fontes de erros nas estimativas do potencial de carbono, Koehler; Watzlawick; Kirchner (2002) comprovam as afirmações feitas por Higuchi; Carvalho Júnior (1994), ajustando equações de regressão para gerar estimativas utilizando dados de biomassa originados de amostragem de campo em Floresta Ombrófila Mista, no estado do Paraná. Na comparação desses dados com as estimativas, observaram que estas subestimam em 12,88\% a quantidade de biomassa real. Segundo Watzlawick (2003), na estimativa de biomassa real utilizando a equação (4), Brown; Gillespie; Lugo (1989) verificaram uma superestimativa de $27,06 \%$.

$$
Y=\exp \left[-3,1141+0,9719 \cdot \ln \left(\text { dap }^{2} . \text { htot }\right)\right]
$$

onde: $\quad \ln =$ logaritmo neperiano;

dap = diâmetro à altura do peito;

htot $=$ altura total.

Para Santos (1996), os dois métodos são alvos de críticas, e as estimativas são desencontradas. As estimativas de Brown ; Lugo (1990), obtidas com base em inventários florestais feitos nos anos 50 e 60 na Floresta Amazônica, variaram de 90 a 397 t ha $^{-1}$, com média ponderada de $268 \mathrm{t} \mathrm{ha}^{-1}$. Fearnside (1991) menciona as mudanças nas estimativas fornecidas por Brown; Lugo (1990), que passaram de 155 para $268 \mathrm{t} \mathrm{ha}^{-1}$, de 1984 para 1989, as quais se aproximam de sua estimativa, que é $290 \mathrm{t} \mathrm{ha}^{-1}$ para florestas densas, nenhuma com verdade de campo, comenta o autor.

Melhorar a estimativa da biomassa de florestas tropicais requer uma ampla base de dados, salienta Santos (1996). O autor acredita que as estimativas da biomassa com base em inventários de volume de florestas melhorem as estimativas de biomassa total acima do solo, porque os dados de volume de inventário florestal são mais abundantes e são, geralmente, coletados em áreas amostrais grandes, com o uso de um método de amostragem planejado, desenvolvido para representar a população de interesse.

\section{FATORES UTILIZADOS EM ESTIMATIVAS DE BIOMASSA}

Fatores de biomassa podem ser definidos em nível de árvores e em nível de talhão, segundo Somogyi et al. (2006). Em nível de árvores, são definidos como:

$$
b f=\frac{m_{1}}{m_{2}}
$$

onde: $\quad$ bf $=$ fator de biomassa em nível de árvore;

$\mathrm{m}_{1}$ e $\mathrm{m}_{2}=$ medidas apropriadas da árvore.

Em nível de talhão, são definidos como:

FLORESTA, Curitiba, PR, v. 38, n. 1, jan./mar. 2008. 


$$
B F=\frac{M_{1}}{M_{2}}=\frac{\sum_{i} m_{1 i}}{\sum_{i} m_{2 i}}
$$

onde: $\quad \mathrm{BF}=$ fator de biomassa em nível de talhão;

$\mathrm{M}_{1}$ e $\mathrm{M}_{2}=$ medidas apropriadas do talhão;

$\mathrm{i}=$ índice de uma árvore;

$\mathrm{m}_{1 \mathrm{i}}$ e $\mathrm{m}_{2 \mathrm{i}}=$ medidas apropriadas das árvores do talhão.

Somogyi et al. (2006) afirmam que vários fatores devem ser usados em estimativas de biomassa, dependendo dos dados disponíveis (árvores ou talhões) e da estimativa desejada. Em casos mais simples e quando são utilizados dados de densidade da madeira, utiliza-se somente um fator de conversão. Quando é necessária a estimativa total de biomassa, mas apenas dados de biomassa comercial estão disponíveis, utiliza-se um fator de expansão. Nesses casos, a conversão e expansão podem ser feitas de várias maneiras. Por exemplo, quando se deseja a estimativa da biomassa total de uma árvore acima do solo, quando somente o volume comercial é disponível, pode-se fazer:

a) expansão do volume comercial para o volume total da árvore, seguida pela conversão para biomassa;

b) conversão do volume comercial da árvore para a biomassa comercial, seguida pela expansão para a biomassa total;

c) conversão e expansão do volume comercial da árvore para a biomassa total da árvore, em um único passo.

Portanto, fatores de biomassa podem ter apenas um componente de expansão ou um componente de conversão, ou ambos podem estar incluídos em um valor combinado.

Esses exemplos podem ser melhor entendidos observando-se a figura 1.

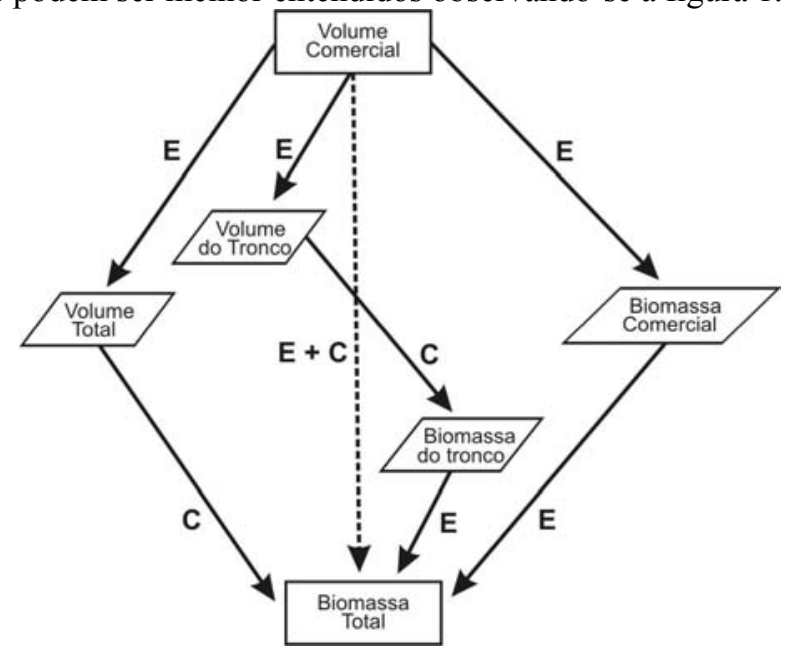

Figura 1. Várias maneiras de se estimar a biomassa total a partir do volume comercial. " $E$ " significa expansão e "C"conversão.

Figure 1. Various ways to estimate total biomass from merchantable volume. " $E$ " denote expansion and " $C$ " conversion.

Fonte: Somogyi et al. (2006).

O fator de expansão pode ser função apenas do dap, como também do dap e da altura. Fatores como função apenas do dap são consideravelmente maiores que os fatores como função do dap e da altura, refletindo em uma superestimativa do total de biomassa acima do solo (BROWN; GILLESPIE; LUGO, 1989). Esses autores ainda mencionam que, como o total da biomassa acima do solo é sempre 
positivo e a biomassa comercial de uma árvore pequena pode ser zero, a relação entre essas duas variáveis pode tender ao infinito. Somogyi et al. (2006) afirmam que esses fatores, além de serem função do dap e da altura, variam também de acordo com a espécie, o tipo e a localização de uma floresta.

Sharp; Lieth; Whigham (1975), estimando biomassa em uma floresta na Carolina do Norte (EUA), com base em dados de inventário florestal, usaram para a constante BEF um valor de $2,0 \mathrm{Mg} \mathrm{m}^{-3}$. Johnson; Sharpe (1983) analisaram a variação desse fator para a maioria dos tipos florestais dos EUA e Canadá, observando que esses valores variaram por tipo florestal e classes de tamanho entre $2,1 \mathrm{Mg} \mathrm{m}^{-3} \mathrm{e}$ $5,0 \mathrm{Mg} \mathrm{m}^{-3}$. Brown; Lugo (1984) aplicaram dois diferentes valores para esse fator (1,6 e 3,0), para uma estimativa de biomassa em florestas tropicais abertas e fechadas, respectivamente. Kauppi; Mielikainen; Kusela (1992), estimando estoque de biomassa e carbono em florestas da Europa, usaram esse fator entre o intervalo de $0,6 \mathrm{Mg} \mathrm{m}^{-3}$ a $0,8 \mathrm{Mg} \mathrm{m}^{-3}$.

Um exemplo do emprego desses fatores em uma equação para estimar biomassa acima do solo a partir de dados de volume pode ser visto da seguinte forma, segundo Brown (1997):

$$
B A S\left(t h a^{-1}\right)=V . W D \cdot B E F
$$

onde: $\quad \mathrm{BAS}=$ biomassa acima do solo;

$\mathrm{V}=$ volume por hectare;

$\mathrm{WD}=$ densidade média da madeira;

$\mathrm{BEF}=$ fator de expansão.

\section{MODELOS UTILIZADOS EM ESTIMATIVAS DE BIOMASSA FLORESTAL}

Um dos principais objetivos em inventários florestais, segundo Couto; Vettorazzo (1999), é a obtenção de estimativas de volume ou massa, sendo para isso muito utilizados modelos matemáticos ou equações de volume ou massa, comercial ou total, que têm geralmente a seguinte forma funcional: $Y=f$ $(\mathrm{d}, \mathrm{h})$, sendo $\mathrm{Y}$ o volume (v) ou a massa (m) individual da árvore, $\mathrm{d}$ o dap e $\mathrm{h}$ a altura total da árvore. Essas equações de volume e massa servem para estimar volumes e massas individuais de árvores e, com base em um método de amostragem, pode-se estimar o volume ou massa de um povoamento florestal (SPURR, 1952; VEIGA, 1981).

Para Vanclay (1994), as equações usadas para estimar biomassa são empíricas, pois descrevem o comportamento da variável resposta sem tentar identificar as causas ou explicar os fenômenos. Para que essas equações forneçam estimativas biologicamente realistas, devem ser formuladas de forma a se comportarem de modo biologicamente realista dentro da amplitude de condições possíveis. Na obtenção da massa de matéria seca dos diferentes componentes da biomassa e sua extrapolação para uma unidade padrão $\left(\mathrm{kg} \mathrm{ha}^{-1}\right)$, é preciso relacionar os dados das massas com caracteres biométricos, tendo assim uma relação chamada "alométrica" (WHITAKKER; WOODWELL ${ }^{4}, 1971$; RUSSO ${ }^{5}, 1983$; KRAPFENBAUER; ANDRAE 6 , 1983; citados por CAMPOS, 1991).

Segundo Crow; Schlaegel (1988), as variáveis mais comumente utilizadas em equações de biomassa são o diâmetro à altura do peito (dap) e a altura total, podendo, em muitos casos, serem combinadas, gerando a variável (dap $\left.{ }^{2} h\right)$.

Com relação ao número de variáveis independentes, Higuchi et al. (1998) citam que modelos de equações alométricas, com apenas uma variável independente (dap), apresentaram resultados tão consistentes quanto os modelos que utilizavam também a altura (h). No entanto, Santos (1996) afirma que uma equação de biomassa que considera tanto o diâmetro quanto a altura deve produzir estimativas melhores do que uma equação que utiliza apenas o diâmetro, por causa da informação adicional fornecida pelo conhecimento da altura.

${ }^{4}$ WHITTAKER, R. H.; WOODWELL, G. M. Measurement of net primary production of forest. In: UNESCO. Productivity of forest ecosystems. Proceedings Brussels Symposium, 1971.

${ }^{5}$ RUSSO, R. O. Mediciones de biomassa en sistemas agroflorestales. Turrialba, Costa Rica. CATIE, 1983. 27 p.

${ }^{6}$ KRAPFENBAUER, A; ANDRAE, F. Inventário de um reflorestamento de araucária de 17 anos em Passo Fundo, RS. Parte I: Inventário de Biomassa. In: Pesquisas austro-brasileiras 1973-1983 sobre Araucaria Angustifolia, Podocarpus lamberti e Eucalyptus saligna. Santa Maria, Universidade Federal de Santa Maria, 1983, p. 16-29.

FLORESTA, Curitiba, PR, v. 38, n. 1, jan./mar. 2008. 
A maioria das estimativas de biomassa viva acima do solo está baseada em avaliações da estrutura da floresta, com medidas de diâmetro, altura e densidade da madeira. É preciso também conhecer a organização espacial das diferentes manchas estruturais de vegetação, como as clareiras, e as diferentes fitofisionomias existentes. Tais variações são atribuídas aos diferentes tipos de solo, aos nutrientes disponíveis, ao clima, ao regime de distúrbios, ao estágio de sucessão, à posição topográfica e ao uso anterior da terra (CLARK; CLARK, 2000). Nesse sentido, Crow; Schlaegel (1988) afirmam que a maioria das equações de regressão para biomassa é desenvolvida para sítios específicos, não sendo aconselhável sua utilização para outras localidades. Chave et al. (2005) citam as principais variáveis preditoras utilizadas nos estudos de biomassa, em ordem decrescente de importância: diâmetro do tronco, densidade da madeira, altura total e tipo florestal.

Uma variedade de modelos de regressão tem sido utilizada na estimativa de biomassa total ou por componente de uma árvore (tronco, galhos, folhas). Crow; Schlaegel (1988) afirmam que equações de biomassa podem ter muitas formas, sendo que as mais comumente utilizadas são as do tipo linear e nãolinear. A escolha de uma dessas formas é função da experiência em sua utilização, da relação entre as variáveis ou pela recomendação da literatura. Segundo (PARDÉ 1980; BALDWIN, 1987; CLARK, 1987; PELZ, 1987), esses tipos podem ser escritos na seguinte forma:

$$
\begin{aligned}
& \text { Linear (erro aditivo): } Y=\beta_{0}+\beta_{1}+\ldots+\beta_{j} X_{j}+\varepsilon \\
& \text { Não-linear (erro aditivo): } Y=\beta_{0} X_{1}^{\beta_{1}} X_{2}^{\beta_{2}} \ldots X_{j}^{\beta_{j}}+\varepsilon \\
& \text { Não-linear (erro multiplicativo): } Y=\beta_{0} X_{1}^{\beta_{1}} X_{2}^{\beta_{2}} \ldots X_{j}^{\beta_{j}}+\varepsilon
\end{aligned}
$$

onde: $Y=$ total da biomassa ou por componente;

$X_{j}=$ variável dendrométrica;

$\beta_{j}=$ parâmetros do modelo;

$\varepsilon=$ termo do erro.

Segundo Parresol (1999), normalmente, os dados de biomassa apresentam heterocedasticidade, isto é, a variância do erro não é constante para todas as observações. O modelo linear pode ser ajustado pelo método dos mínimos quadrados, enquanto que no modelo não-linear (erro aditivo) utilizam-se procedimentos iterativos na estimativa dos parâmetros. Para o modelo não-linear (erro multiplicativo), geralmente é feita uma transformação logarítmica, tornando-o um modelo linear. Nessa forma, os parâmetros são então estimados por mínimos quadrados, e quando transformado em modelo logaritmo, a variância do erro geralmente torna-se constante (homocedasticidade).

Esse modelo apresenta-se da seguinte forma:

$$
\ln Y=\ln \beta_{0}+\beta_{1} \ln X_{1}+\ldots+\beta_{j} \ln X_{j}+\ln \varepsilon
$$

$\mathrm{Na}$ escolha entre uma função linear ou não-linear objetivando estimativa de biomassa, Cunia (1986) afirma que as lineares possuem algumas vantagens. Assim, como a maior parte da teoria estatística tem sido desenvolvida para funções lineares e sendo o método dos mínimos quadrados muito conhecido, a sua aplicação é simples e pode ser estendida para todos os tipos de funções lineares e também na soma das funções de biomassa de cada componente de uma árvore. Outra grande vantagem apontada por esse autor é que o erro da função linear de regressão pode ser representado em uma forma conveniente, combinando facilmente com o erro amostral proveniente do inventário. A única desvantagem da função linear é que não pode ser aplicada para dados que se encontram fora do intervalo amostral, enquanto que a não-linear pode ser aplicada nessa região.

Segundo Chave et al. (2005), pelo fato das florestas tropicais apresentarem aproximadamente 300 espécies em um hectare, a utilização de modelos de regressão em estudos de biomassa nesse tipo florestal não é feita por espécie, e sim por grupos de espécies. Esses autores afirmam que, normalmente, as informações dendrométricas são extraídas de um pequeno número de árvores que são derrubadas com uma pequena amplitude diamétrica. Iszo explica porque dois modelos produzem estimativas diferentes para um mesmo tipo florestal. 
As equações alométricas mais comumente utilizadas para a estimativa de biomassa são as propostas por Brown; Gillespie; Lugo (1989), para floresta tropical primária, e por Uhl; Buschbacher; Serrão (1988), para o caso de floresta secundária, sendo função do dap e da altura total do indivíduo:

$$
\begin{array}{ll}
y=0,44 *\left(\text { dap }^{2} * h\right)^{0,9719} & \text { (floresta primária) } \\
\ln y=-2,17+1,02 \ln (\text { dap })^{2}+0,39 \ln h & \text { (floresta secundária) }
\end{array}
$$

onde: $y=$ biomassa aérea (kg/árvore);

dap $=$ diâmetro do caule a $1,3 \mathrm{~m}$ de altura do solo $(\mathrm{cm})$;

$h=$ altura total do indivíduo (m).

Abaixo são descritas algumas equações e seus autores, utilizadas para estimar biomassa acima do solo em regiões tropicais com florestas naturais, a partir de dados de inventário florestal:

$$
\begin{aligned}
& Y=\exp \{-1,996+2,32 * \ln (d)\}(\text { Brown; Gillespie; Lugo, 1989) } \\
& Y=10^{\{-0,535+\log (B A)\}}(\text { Martinez-Yrizar et al., 1992) } \\
& Y=42,69-12,800(d)+1,242\left(d^{2}\right)(\text { Brown; Gillespie; Lugo, 1989) } \\
& Y=\exp \{-2,134+2,530 * \ln (d)\} \text { (Brown; Gillespie; Lugo, 1989) } \\
& Y=2,297-6,95(d)+0,740\left(d^{2}\right) \text { (Brown; Iverson, 1992) }
\end{aligned}
$$

onde: $Y=$ biomassa por árvore $(\mathrm{kg})$;

$d=$ diâmetro à altura do peito $(\mathrm{cm})$;

$B A=$ área basal $\left(\mathrm{cm}^{2}\right)$.

Obs.: nas equações (14), (16), (17) e (18) utilizaram-se duas classes de dap: $<30$ e $\geq 30 \mathrm{~cm}$, com um erro considerado de $5 \%$.

Tanizaki (2000), com base em estudos anteriores, selecionou a equação alométrica abaixo como sendo adequada a algumas formações da Mata Atlântica, como, por exemplo, Floresta Ombrófila Mista e Floresta Ombrófila Densa.

$$
B V A S \sec a=2,718^{\left(-2,5202+2,14^{*} L N(\text { dap })+0,4644^{*} L N(h)\right)}
$$

onde: $d a p=$ diâmetro à altura do peito;

$h=$ altura total.

Objetivando a seleção de equações de volume e massa seca comercial para Pinus taeda, espécie do gênero Pinus; Couto; Vettorazzo (1999) consideraram o modelo da variável combinada (Y $=\beta_{0}+\beta_{1}$ $\mathrm{d}^{2} \mathrm{~h}$ ) o mais indicado, tanto em termos de precisão quanto pelo ajustamento obtido para estimar volumes e massas, com base nos critérios adotados para avaliação comparativa citados acima.

Muitas pesquisas sobre ajustes de equações de regressão para se estimar biomassa utilizando-se modelos não-lineares tem a seguinte forma:

$$
\hat{Y}=\beta_{1} X^{\beta_{2}}
$$

Colocando o logaritmo natural em cada lado e podendo ser ajustada pelo método dos mínimos quadrados, essa equação fica assim desenvolvida (BROWN; GILLESPIE; LUGO 1989):

$$
\ln (Y)=\ln \left(\beta_{1}\right)+\beta_{2}(\ln (X))=\alpha_{1}+\alpha_{2}(\ln (X))
$$

De acordo com Chave et al. (2005), a estimativa da biomassa acima do solo (AGB) para uma árvore pode ser realizada pela seguinte expressão:

$$
A G B=F . \rho .\left(\frac{\pi D^{2}}{4}\right) \cdot H
$$

onde: $\mathrm{ABG}=$ biomassa acima do solo;

$\mathrm{F}=$ fator multiplicativo que depende do afilamento da árvore; 
$\rho=$ densidade específica da madeira;

$\mathrm{D}=$ diâmetro à altura do peito;

$\mathrm{H}=$ altura total.

Em estimativa de biomassa para florestas tropicais da América, Ásia e África, Chave et al. (2005) utilizaram os seguintes modelos de regressão:

Modelo I:

$$
\ln (A G B)=\beta_{0}+\beta_{1} \ln (D)+\beta_{2} \ln (H)+\beta_{3} \ln (\rho)
$$

onde: $\mathrm{AGB}=$ biomassa acima do solo;

$\mathrm{D}=$ diâmetro à altura do peito;

$\mathrm{H}=$ altura total;

$\rho=$ densidade específica da madeira;

$\beta_{0}, \beta_{1}, \beta_{2}, \beta_{3=}$ coeficientes do modelo.

Modelo II:

$$
\ln (A G B)=\beta_{0}+\beta_{1} \ln (D)+\beta_{2}(\ln (D))^{2}+\beta_{3}(\ln (D))^{3}+\beta_{3} \ln (\rho)
$$

onde: $\mathrm{AGB}=$ biomassa acima do solo;

$\mathrm{D}=$ diâmetro à altura do peito;

$\rho=$ densidade específica da madeira;

$\beta_{0}, \beta_{1}, \beta_{2}, \beta_{3}$ coeficientes do modelo.

Segundo Cunia (1986), uma questão que não pode deixar de ser mencionada quando se utilizam funções de regressão para estimativa de biomassa é aquela relacionada aos erros que estão inseridos nessas estimativas. Para esse autor, tais erros são originados, por exemplo, durante o processo de seleção das árvores amostrais e de coleta dos dados, que, quando realizado em diferentes ocasiões, poderá gerar ajustes com diferentes resultados; por medições das mesmas amostras feitas em diferentes ocasiões por equipes distintas; pela utilização de diferentes modelos de regressão diante do mesmo conjunto de dados; pela utilização de um mesmo modelo de regressão para várias populações florestais.

Para a seleção dos melhores modelos, podem ser adotados os seguintes critérios, segundo Couto (1977), Draper; Smith (1981), Ahrens (1983), Campos; Trevizol Júnior; Paula Neto (1985) e Montgomery; Peck (1982):

a) exame do quadro da análise de variância (SQR), soma de quadrados dos resíduos, quadrado médio dos resíduos (QMR), teste "F" para o modelo completo e teste " $F$ " seqüencial;

b) análise das medidas de precisão: coeficiente de determinação $\left(\mathrm{R}^{2}\right)$, erro padrão da estimativa ou erro padrão residual $\left(\mathrm{S}_{\mathrm{yx}}\right)$ e erro padrão da estimativa expresso como uma porcentagem da média aritmética da variável dependente $\left(\mathrm{S}_{\mathrm{yx}} \%\right)$, sendo, neste caso, interpretado de forma análoga ao coeficiente de variação;

c) distribuição gráfica dos valores residuais;

d) exame das estimativas dos parâmetros da equação pelo teste t.

Schlaegel (1982) ${ }^{7}$, citado por Crown; Schlaegel (1988), recomenda que seja considerada uma série de estatísticas para a avaliação do melhor ajuste quando se pretende comparar modelos para estimativas de biomassa: $\mathrm{R}^{2}$ (coeficiente de determinação), $\mathrm{S}_{\mathrm{e}}$ (erro padrão da estimativa), CV (coeficiente de variação), I (índice de Furnival), S(\%) (erro padrão em porcentagem), $\mathrm{P}_{\mathrm{e}}$ (erro percentual), que representa a diferença relativa em porcentagem entre a massa estimada e a massa real, e o intervalo de confiança dos valores preditos.

Koehler; Watzlawick; Kirchner (2002), estudando biomassa e carbono em uma Floresta Ombrófila Mista, no estado do Paraná, Brasil, elaboraram um gráfico sobre a relação entre a biomassa

\footnotetext{
${ }^{7}$ SCHLAEGEL, B. E. 1982. Testing, reporting, and using biomass estimation models. p. 95-112 in Proc. 1981 southern forest biomass workshop.
} 
total de cada árvore e o seu DAP, objetivando determinar a amplitude e a forma da relação entre essas variáveis, bem como obter uma estimativa inicial da homogeneidade da variância condicional. Construíram também um gráfico da distribuição dos resíduos da equação de regressão ajustada para estimar a biomassa total.

Sanquetta et al. (2001) e Watzlawick et al. (2001), testando modelos para Pinus taeda e Araucaria angustifolia, respectivamente, em povoamentos florestais no sul do estado do Paraná, Brasil, utilizaram as estatísticas "erro padrão da estimativa" e "coeficiente de determinação" na escolha de equações para fuste.

Sanquetta (2002) salienta que, no ajuste de equações em estudos de biomassa e carbono, deve-se ter o cuidado sempre de avaliar com justiça as melhores equações, através da avaliação das estatísticas indicadoras de qualidade de ajuste (erro padrão da estimativa, coeficiente de determinação, etc.), além de um exame gráfico do comportamento dos resíduos.

Em um trabalho denominado "Quantificação da biomassa em uma Floresta Estacional Decidual em Itaara, estado do Rio Grande do Sul”, Vogel; Schumacher; Trüby (2006) utilizaram as estatísticas coeficiente de determinação e erro padrão da estimativa como critério para a escolha das equações na estimativa da biomassa para os diversos componentes das árvores.

\section{Quantificação do estoque de carbono}

O armazenamento de carbono em ecossistemas florestais é um parâmetro básico para se estudar a troca desse elemento entre esses ambientes e a atmosfera, e um dado essencial na estimativa da absorção e emissão desse elemento por esses ambientes (WANG et al., 1995). Smith et al. (2004) mencionam que estudos sobre seqüestro de carbono são importantes na avaliação de uma floresta como recurso natural, como também na relação entre mudanças climáticas e o acúmulo de gases do efeito estufa na atmosfera, uma vez que as florestas removem o dióxido de carbono da atmosfera e o estocam na forma orgânica.

A madeira não é uma substância química uniforme ou definida. Ela é formada por um agregado de componentes orgânicos e inorgânicos, muitos dos quais ainda desconhecidos. Frizzo; $\operatorname{Silva}^{8}$ (1998) citados por Watzlawick et al. (2004), complementam dizendo que a quantidade desses componentes varia de uma espécie para outra, dentro de uma mesma espécie vegetal, de região para região, em uma mesma árvore e até mesmo de uma célula para outra, e que, de uma maneira geral, a composição química da madeira tanto de folhosas como coníferas apresentam cerca de $50 \%$ de $\mathrm{C}, 6 \%$ de $\mathrm{H}$ e $44 \%$ de $\mathrm{O}$, pequenos teores de $\mathrm{N}$ e minerais determinados como cinzas, os quais são desprezados quando se consideram os teores desses elementos no sentido geral.

Em geral, há duas diferentes maneiras de se mensurar as perdas ou o acúmulo de carbono em uma região, segundo Lindner; Karjalainen (2007): mensurando as mudanças no estoque e mensurando o fluxo de entrada e de saída. Alternativas metodológicas têm sido desenvolvidas para se medir o fluxo desse elemento em ecossistemas, como, por exemplo, o estudo de modelos que medem a sua concentração na atmosfera, a utilização do sensoriamento remoto, modelos de simulação e modelos que relacionam a retenção de nitrogênio e carbono em ecossistemas. A metodologia padrão utilizada atualmente para se fazer essas mensurações baseia-se em dados de inventário florestal. Para se estimar a mudança em estoque, por exemplo, são utilizados dados de inventários florestais consecutivos. Hu; Liu; Jiao (2007) estudaram a variação no estoque de carbono nas florestas da China com base em dados de inventário florestal obtidos a cada três anos, entre 1973 e 2003.

A partir de dados de inventário florestal, podem-se determinar relações alométricas que utilizam variáveis como o fator de expansão de biomassa e a densidade média de carbono por espécie ou por tipo florestal, que convertem volume de madeira em biomassa e posteriormente em carbono (LINDNER; KARJALAINEN, 2007).

Smith et al. (2004) afirmam que, dependendo do detalhamento de um inventário florestal, tais estimativas podem ser classificadas em três grupos: por área, em que se levam em consideração avaliações por região, por tipo florestal ou classes de volume; em nível de talhão, em que são utilizados

${ }^{8}$ FRIZZO, S. M. B.; SILVA, M. G. Composição química da madeira. In: apontamentos de química da madeira. Santa Maria: UFSM/Departamento de Química, 1998. p. 3-17.

FLORESTA, Curitiba, PR, v. 38, n. 1, jan./mar. 2008. 
dados medidos ou calculados, como o volume e a idade; em nível de árvores, em que há a disponibilidade de dados mais específicos obtidos por amostragem.

Higuchi (2004) afirma que a estimativa de estoque de carbono pode ser obtida do produto da biomassa florestal pela concentração de carbono. A concentração de carbono na vegetação obtida por Higuchi e Carvalho Jr. (1994) está em torno de 48\%, valor este que está dentro dos limites de concentrações em florestas tropicais (entre 46 e $52 \%$ ).

Segundo Schneider et al. (2004), o teor desse elemento tem sido considerado constante, variando pouco entre as diversas espécies já estudadas. Wang ${ }^{9}$ et al. (2001), citado por Schneider et al. (2004), na determinação do estoque de carbono na China, utilizaram um fator linear de concentração de carbono igual a 0,45 , e aplicaram um fator de conversão do volume em biomassa florestal para cada grupo florestal do país. Mencionaram que essa conversão pode ser influenciada por fatores como a idade e o sítio.

Para Koehler; Watzlawick; Kirchner (2002), o uso de fatores para espécie da qual não se conhece o verdadeiro teor pode levar a resultados de sub ou superestimativas do estoque de carbono.

Segundo Schneider et al. (2004), no Inventário Ecológico e Florestal da Espanha, foram levantadas as quantidades de madeira, biomassa, nutrientes e carbono. A quantidade de carbono variou por fração da parte aérea para cada espécie, bem como entre coníferas e folhosas. As madeiras de coníferas apresentaram 49,9 a 51,1 g de carbono por cada $100 \mathrm{~g}$ de madeira (massa seca), enquanto que as folhosas apresentaram valores médios entre 47,2 e 48,6 g de carbono para cada $100 \mathrm{~g}$ de madeira (massa seca). Os autores salientam que estimativas de estoque de carbono com base em dados de inventário florestal são preferíveis à maioria das outras fontes de informação, porque se consegue abranger, com maior realidade, as fontes de variação dos dados básicos acerca do volume por hectare, em todos os tipos florestais e sob diferentes condições biológicas.

Um dos métodos mais usados para estimar o estoque de carbono em florestas, por reduzir as incertezas nas estimativas, é o método de derivação do volume em biomassa e carbono. Segundo Schneider et al. (2004), tal método foi utilizado nas florestas boreais do Canadá (APPS; KURZ, 1994), nas florestas dos Estados Unidos da América (TURNER et al., 1995), nas florestas da Rússia (ALEXEYEV et al., 1995) e nas florestas da China (FAN et al. ${ }^{10}, 1998$ ). Nesse método, determina-se um fator de conversão para se estimar o estoque de carbono da vegetação obtido pela proporção entre a biomassa e o volume da floresta, variando com o tipo florestal (espécies), região (qualidade do sítio), estágio de desenvolvimento (classe de idade) e atividade humana, sendo necessário conhecer a densidade básica da madeira, o conteúdo de carbono e a proporção do volume para a biomassa total.

$\mathrm{Na}$ estimativa do estoque de carbono em povoamentos eqüiâneos de Acácia mearnsii, na região da Encosta Inferior do Sudeste, no Rio Grande do Sul, utilizando o método de derivação do volume em biomassa e carbono, Schneider et al. (2005) afirmam que esse método mostrou-se eficiente na determinação do estoque de carbono, pois a diferença relativa média foi de apenas $4,4 \%$, quando considerada toda a amostragem, independentemente da idade dos povoamentos. Para essa estimativa, foi utilizada a seguinte expressão:

$$
C i=\sum_{i=1}^{n}\{(\text { Vi.Dbi.Cc }) / P b i\}
$$

onde: $\mathrm{Ci}=$ carbono estocado na i-ésima idade ou tipo florestal;

$\mathrm{Vi}=$ estoque real inventariado na i-ésima idade ou tipo florestal, $\mathrm{em} \mathrm{m}^{3} \mathrm{ha}^{-1}$;

$\mathrm{Dbi}=$ densidade básica da madeira da i-ésima idade, em $\mathrm{g} / \mathrm{cm}^{3}$;

$\mathrm{Pbi}$ = proporção de biomassa do tronco com casca em relação à biomassa total na i-ésima idade ou tipo florestal;

$\mathrm{Cc}=$ concentração de carbono;

$\mathrm{n}=$ número de idades ou tipos florestais.

\footnotetext{
${ }^{9}$ WANG, X.; FENG, Z.; OUY ANG, Z. The impact of human disturbance on vegetative carbon storage in forest ecosystems in China. Forest Ecology and Management. V. 148, p. 117-123. 2001.

${ }^{10}$ FANG, J.; WANG, G. G.; LIU, G.; XU, S. Forest biomass of Masson pine in Huitong, Human Province. Forest Resources. V. 1, p. 117-134. 1998.
} 
Visando analisar a contribuição das plantações florestais chilenas (representadas pelas espécies Pinus radiata do gênero Pinus e Eucalyptus globulus do gênero Eucalyptus) na fixação de carbono atmosférico no ano de 1995, Mery; Kanninen ${ }^{11}$ (1998), citados por Barra (2002), desenvolveram o seguinte modelo para estimar esse elemento:

$$
\mathrm{C}=\text { V.p.c. } \alpha
$$

onde: $\mathrm{C}=$ Carbono total nas árvores em toneladas;

$\mathrm{V}=$ volume total em pé cúbico;

$\rho=$ densidade média da madeira seca;

$\mathrm{c}=0,5$ (conteúdo de carbono na biomassa);

$\alpha=1,89$ (fator de expansão da biomassa do fuste à biomassa total).

A fixação de carbono nas duas espécies estudadas alcançou 92 milhões de toneladas de carbono, gerando um valor médio por hectare de 48,8 toneladas.

Com o objetivo de quantificar o volume de carbono em uma floresta manejada de forma sustentada e compará-lo com as emissões anuais de origem antropogênica no estado alemão de RheinPfals; Schöne; Schulte (1999) relatam que as florestas armazenam em média $250 \mathrm{t} \mathrm{ha}^{-1}$ de carbono, quantidade equivalente às emissões de 20 anos naquele estado. $\mathrm{O}$ armazenamento de carbono foi quantificado considerando a quantidade de biomassa da parte aérea, do solo, na serapilheira, no húmus, nos produtos da madeira e nas árvores mortas. Nessa estimativa, foi utilizada a seguinte equação:

$$
\mathrm{C}=\mathrm{V} . \mathrm{Db} . \mathrm{Fb} . \mathrm{Fc}
$$

onde: $\mathrm{C}=$ carbono em toneladas;

$\mathrm{V}=$ volume em $\mathrm{m}^{3}$ sem casca;

$\mathrm{Db}=$ densidade básica da madeira $-\mathrm{t}^{-3}$;

$\mathrm{Fb}$ = fator de expansão para correção do volume em massa seca de toda a biomassa de um povoamento e a massa seca do volume comercial;

$\mathrm{Fc}=$ fator para a determinação da massa seca da biomassa em carbono $(0,50)$.

Higuchi; Carvalho Júnior (1994), analisando várias espécies da floresta tropical úmida densa de terra firme, na região de Manaus (AM), obtiveram as seguintes conclusões sobre o teor médio de carbono: tronco (48,4\%), liteira (39,3\%), plântulas $(46,5 \%)$, mudas $(49,3 \%)$ e galhos vivos $(46,8 \%)$.

Para Birdsey (1992), estimativas de carbono em estudos passados, como os de Houghton et al. (1985), apontam um intervalo de 45 a 50\% da biomassa. Porém, Koch (1989) afirma que, para os Estados Unidos, de uma maneira geral, a porcentagem média de carbono para madeira mole é de $52,1 \%$ e para madeira dura é de 49,1, com alguma variação conforme a região. O fator final usado na conversão de volume (pé cúbico) em carbono (libra) ficou entre 11,41 a 17,76 para madeiras moles e 11,76 a 19,82 para madeiras duras. Esse fator é obtido multiplicando-se a densidade específica da madeira pelo peso de um pé cúbico de água (64 libras ou 29,03 kg) pela percentagem de carbono, e sua unidade é $\mathrm{g} / \mathrm{cm}^{3}$.libra.

$\mathrm{Na}$ estimativa de carbono estocado no fuste de árvores de eucalipto, Soares et. al (2005) utilizaram o modelo linearizado de Schumacher; Hall $(1993)^{12}$, com as respectivas medidas de diâmetro à altura do peito (dap) e altura total (ht):

$$
\operatorname{Ln} Y=\beta_{0}+\beta_{1} \text { Lndap }+\beta_{2} \operatorname{Lnht}+\varepsilon
$$

onde: $L n=$ logaritmo neperiano;

$Y=$ carbono total no fuste (madeira seca) - $\mathrm{CF}-$, ou carbono na madeira $-\mathrm{CM}-$, em $\mathrm{kg}$;

$\beta_{i}=$ parâmetros do modelo, para $\mathrm{i}=1,2$ e 3 ;

$\varepsilon=$ erro aleatório;

dap = diâmetro à altura do peito;

\footnotetext{
${ }^{11}$ MERY, G.; KANNINEN, M. Las plantaciones forestales y el secuestro de carbono en Chile. In: CONGRESSO LATINOAMERICANO IUFRO, 1., 1998. Valdivia, Chile. 1998. CD-ROM.

${ }^{12}$ SHUMACHER, F. X.; HALL, F. S. Logarithmic expression of timber-tree volume. Journal of Agricultural Research, v.47, n.9, p. 719-734, 1993.
} 
$h t=$ altura total da árvore.

Nesse mesmo trabalho, para avaliar a precisão das equações, foram utilizados o coeficiente de determinação $\left(\mathrm{R}^{2}\right)$, o erro-padrão da estimativa $\left(\mathrm{S}_{\mathrm{y} . \mathrm{x}}\right)$ e a análise gráfica de resíduos porcentuais $(\mathrm{R} \%)$, obtidos por:

$$
R \%=\frac{Y_{e s t}-Y_{o b s}}{Y_{o b s}} .100
$$

\section{CONSIDERAÇÕES FINAIS}

É inquestionável a importância de se realizar estudos sobre biomassa e estoque de carbono em formações florestais na atualidade. A tomada de decisões no manejo dos recursos florestais, o interesse na completa utilização da árvore (raízes, tronco, ramos), conhecer as condições fitossanitárias de um ecossistema, fornecer elementos para cálculos das emissões de gases do efeito estufa pela queima e decomposição da matéria orgânica em sistemas naturais e antropizados são algumas dessas razões. Sendo assim, as estimativas de biomassa e estoque de carbono são necessárias para um melhor entendimento sobre as mudanças ambientais globais.

Nas estimativas em que são utilizados dados de inventário florestal, apesar de se ter a vantagem de não precisar calcular o volume individual das árvores, a principal desvantagem é que não se têm dados de todas as classes de diâmetro, pois geralmente o interesse é pela parte comercial de uma floresta, com as espécies de maior interesse. Quando são utilizadas equações de regressão, recomenda-se que essa estimativa seja correlacionada não só com a variável diâmetro, mas também com a variável altura.

Outra questão que deve ser levantada é com relação aos locais de um ecossistema que são considerados em uma estimativa de biomassa. Uma vez que a maioria dessas estimativas considera apenas as partes vivas das plantas acima do solo, e com um diâmetro mínimo, sugere-se que sejam consideradas também as árvores menores, a vegetação rasteira no solo, raízes e a vegetação morta tanto acima quanto abaixo do solo, em pé ou caída.

Alguns autores questionam os resultados das amostragens destrutivas. Afirmam que possuem valores mais altos do que as estimativas volumétricas, pois são realizadas por várias pessoas e estão sujeitas a escolhas tendenciosas dos locais de estudo, como, por exemplo, locais menos perturbados que a média real.

No que tange às equações de regressão, as incertezas aumentam com a extrapolação de uma equação alométrica. Uma vez que diferentes ambientes são dominados por diferentes espécies, conseqüentemente as relações alométricas também são diferentes.

Fatores ou equações são amplamente usados atualmente em estudos de biomassa e carbono, mas muito pouco se sabe sobre erros envolvidos em tais estudos (SOMOGYI, 2006). Sobre essa questão, Jenkins et al. (2003) listaram várias fontes de erros, que vão desde a metodologia de amostragem até o processamento dos dados:

- fatores ou equações desenvolvidos para uma determinada região não podem ser aplicados em regiões distintas;

- fatores ou equações desenvolvidos para uma espécie ou grupo de espécies não podem ser aplicados para outras espécies;

- multiplicação de vários fatores de biomassa, como densidade da madeira e fator de expansão, ao invés da utilização de fatores combinados;

- amostras de árvores e de densidade da madeira que não sejam representativas da populaçãoalvo.

\section{REFERÊNCIAS}

AHRENS, S. Importância da distribuição de resíduos de regressão na seleção de equações de volume. Silvicultura, São Paulo, v. 8, n. 28, p. 609-614, 1983. 
ALEXEIEV, V.; BIRDSEY, R.; STAKANOV, V.; KOROTKOV, I. Carbon in vegetation of Russian forests. Methods to estimate storage and geographical distribution. Water and soil, [S.1], v. 82, p. 271$382,1995$.

ANDRAE, F.; KRAPFENBAUER, A. Inventário de um reflorestamento de araucária de 17 anos em Passo Fundo, R.S. In: Pesquisas austro-brasileiras 1973-1982 sobre Araucária angustifolia, Podocarpus lambertii e Eucalyptus saligna: inventário de nutrientes. Santa Maria: UFSM, 1983. p. 30-35.

APPS, M. J.; KURZ, W. A. The role of Canadian forests in the global carbon budget. In: KANNINEN, M. (Ed.). Carbon balance of world's forested ecosystems: towards a global assessment. Finland: SILMU, 1994. p. 14-39.

BALDWIN, V. C. JR. A Summary of equations for predicting biomass os planted southem pines. In: Estimating tree biomass regressions and their contribution to the error of forest inventory estimates. Broomall: USDA. Forest Service, 1987. p. 157-171. Proceedings of the Workshop on tree biomass regression functions and their contribution to the error of forest inventory estimates. (General Techical Report NE-117).

BARRA, O. S. V. Experiência do Chile em estudos de carbono. In: SANQUETTA, C. R. et al. (Eds.). As florestas e o carbono. Curitiba, [s.n.], 2002. p. 237-250.

BIRDSEY, R. A. Carbon storage and accumulation in United States forest ecosystems. Washington, DC: USDA Forest Service, 1992. (General Techical Report WO-59).

BOSCOLO, M.; BUONGIORNO, J. Managing a tropical rainforest for timber, carbon storage and tree diversity. Commonwealth Forestry Review, Oxford, v. 76, n. 4, p. 246-254, 1997.

BROWN, S.; LUGO, A. E. Biomass of tropical forests: a new estimate based on forest volumes. Science, Washington, DC, n. 223, p. 1290-1293, 1984.

BROWN, S.; LUGO, A. E.; CHAPMAN, J. Biomass of tropical tree plantations and its implication for the global carbon budget. Canadian Journal of Forest Research, Ottawa, v. 13, p. 390-394, 1986.

BROWN, S.; GILLESPIE, A. J. R.; LUGO, A. E. Biomass estimation methods for tropical forests with applications to forest inventory data. Forest Science, Lawrence, v. 35, p. 881-902, 1989.

BROWN, S.; LUGO, A. E. Biomass estimates moist forest the Brasilian Amazon. 2.ed. [S1.: s.n.], 1990. 25 p.

BROWN, S.; IVERSON, L. R. Biomass estimates for tropical forests. World Resources Review, [S.l.], n. 4, p. 366-384, 1992.

BROWN, S. Estimating biomass and biomass change of tropical forests: a primer. Rome: FAO, 1997. $55 \mathrm{p}$.

BROWN, S. L.; SCHOEDER, P.; KERN, J. S. Spatial distribution of biomass in forests of the eastern USA. Forest Ecology and Management, Amsterdam, v. 123, n. 1-3, p. 81-90, 1999.

CAMPOS, J. C. C.; TREVIZOL JÚNIOR, T. L.; PAULA NETO, F. de. Ainda, sobre a seleção de equações de volume. Revista Árvore, Viçosa, MG, v. 9, n. 2, p. 115-126, 1985.

CAMPOS, M. A. A. Balanço de biomassa e nutrientes em povoamentos de Ilex paraguariensis. Avaliação na safra e na safrinha. 106 f. Dissertação (Mestrado em Engenharia Florestal) - Setor de Ciências Agrárias, Universidade Federal do Paraná, Curitiba, 1991.

CAMPOS, C. P. de. A conservação das florestas no Brasil, mudança do clima e o mecanismo de desenvolvimento limpo no Protocolo de Quioto. 169 f. Dissertação (Mestrado em Ciências em Planejamento Estratégico) - Coordenação dos Programas de Pós-Graduação em Engenharia, Universidade Federal do Rio de Janeiro, Rio de Janeiro, 2001.

CHAVE, J.; ANDALO, C.; BROWN, S.; CAIRNS, M. A.; CHAMBERS, J. Q.; EAMUS, D.; FÖLSTER, H.; FROMARD, F.; HIGUCHI, N.; KIRA, T.; LESCURE, J. P.; NELSON, B. W.; OGAWA, H.; PUIG, H.; RIÉRA, B.; YAMAKURA, T. Tree allometry and improved estimation of carbon stocks and balance in tropical forests. Oecologia, Berlin, v. 145, p. 87-99, 2005. 
CLARK, A. Predicting biomass production in the South. In: ANNUAL FOREST SYMPOSIUM, 31., 1982, Baton Rouge, LA. Predicting growth and yield in the Mid-south. Baton Rouge: Louisiana State University, 1982. p. 119-139.

CLARK, A. Summary of biomass equations available for softwood and hardwood species in the southem United States. In: Estimating tree biomass regressions and their error. Broomall: USDA. Forest Service, 1987. p. 173-188. Proceedings of the Workshop on tree biomass regression functions and their contribution to the error of forest inventory estimates. (General Techical Report NE-117).

CLARK, D. B.; CLARK, D. A. Landscape-scale variation in forest structure and biomass in a tropical rain forest. Forest Ecology and Management, Amsterdam, v. 137, n. 1-3, p. 185-198, 2000.

ClUTER, J. L.; FORSTON, J. C.; PIENAAR, L. V. et al. Timber Management: a quantitative approach. Malabar: Krieger, 1992. p. 3-29.

COOPER, C. F. Carbon storage in managed forest. Canadian Journal of Forest Research, Ottawa, v. 13, n. 1, p. 155-165, 1983.

COUTO, H. T. Z. do. Tabelas de volume para brotação de touças de Eucalyptus saligna Sm. IPEF, Piracicaba, n. 15, p. 117-121, 1977.

COUTO, H. T. Z. do; VETTORAZZO, S. S. Seleção de equações de volume e peso seco comercial para Pinus taeda. Cerne, Lavras, M. G., v. 5, n. 1, p. 69-80, 1999.

CROW, T. R.; SCHLAEGEL, B. E. A guide to using regression equations for estimating tree biomass. Northern Journal of Applied Forestry, United States, v. 5, n. 1, Mar., 1988.

CUNIA, T. R. Construction of tree biomass tables by linear regression techniques. In: Estimating tree biomass regression and their error. Broomall: USDA. Forest Service, 1986. p. 27-36. Proceedings of the Workshop on tree biomass regression functions and their contribution to the error of forest inventory estimates. (General Techical Report NE-117).

DIXON, R. K.; HOUGHTON, R. A.; SOLOMON, A. M.; TREXLER, M. C.; WISNIEVSKI, J. Carbon Pools and Flux of Global Forest Ecosystems. Science, Washington, DC, v. 263, p. 185-190, 1994.

DRAPER, N. R.; SMITH, H. Applied Regression Analysis. 2 ed. New York: J. Wiley \& Sons, 1981. $709 \mathrm{p}$.

FAN, S.; GLOOR M.; MAHLMAN, J.; PACALA, S.; SARMIENTO, J.; TAKAHASHI, T. A large terrestrial carbon sink in north America implied by atmospheric and oceanic carbon dioxide models. Science, Washington, DC, n. 282, p. 386-387, 1998.

FANG, J. Y.; WANG, Z. M. Forest biomass estimation at regional and global levels, with special reference to China's forest biomass. Ecological Research, Tsukuda, n. 16, p. 587-592, 2001.

FEARNSIDE, P. M. Greenhouse gas contributions from deforestation in Brazilian Amazonia. In: LEVINE, J. S. (Ed.) Global Biomass Burning: Atmospheric Climatic and Biospheric Implications. Boston: MIT, 1991. p. 92-105.

FEARNSIDE, P. M. Biomassa das florestas amazônicas brasileiras. In: SEMINÁRIO EMISSÃO X SEQUESTRO DE CO2 - UMA NOVA OPORTUNIDADE DE NEGÓCIOS PARA O BRASIL, Rio de Janeiro. Anais... Rio de Janeiro: CURD, 1994. p. 95-124.

FEARNSIDE, P. M. Amazonian deforestation and global warming: carbon stocks in vegetation replacing Brazil's Amazon Forest. Forest Ecology and Management, Amsterdam, v. 80, n. 1-3, p. 21-34, 1996.

FEARNSIDE, P. M. Wood density for estimating forest biomass in Brazilian Amazonia. Forest Ecology and Management, Amsterdam, v. 90, n. 1-3, p. 59-87, 1997.

FEARNSIDE, P. M. et al. Tropical forest burning in Brazilian Amazonian: measurement of biomass loading, burning efficiency and charcoal formation at Altamira, Pará. Forest Ecology and Management, Amsterdam, v. 123, n. 1-3, p. 65-79, 1999. 
FUKUDA, M.; IEHARA, T.; MATSUMOTO, M. Carbon stock estimates for sugi and hinoki forests in Japan. Forest Ecology and Management, Amsterdam, v. 184, n. 1-3, p. 1-16, 2003.

GARDNER, R. H.; MANKIN, J. B. analysis of biomass allocation in forest ecosystems of the IBP. In: REICHLE, P. D. Dynamic properties of forest ecosystems. Cambridge, Cambridge Universyru Press, 1981. p. 451-497.

GOLLEY, F. B.; McGINNIS, J. T.; CLEMENTS, R. G. La biomassa y la estrutura mineral de algunos bosques de Darién, Panamá. Turrialba, San Jose, CR, v. 21, n. 2, p. 189-196, 1971.

GUEDES, B.; ARGOLA, J.; PUNÁ, N; MICHONGA, E.; MONTEIRO, J. Estudo da biomassa florestal numa floresta aberta de miombo no distrito de Bárué, Manica. Moçambique: Universidade Eduardo Mondlane, Faculdade de Agronomia e Engenharia Florestal, 2001. pt. 2. Relatório das actividades de julho/2001.

HARIPRIYA, G. S. Estimates of biomass in Indiam forests. Biomass and Bioenergy, Oxford, GB, v. 19, p. $245-258,2000$.

HIGUCHI, N.; CARVALHO JÚNIOR, J. A. Fitomassa e conteúdo de carbono de espécies arbóreas da Amazônia. In: SEMINÁRIO EMISSÃO x SEQÜESTRO DE $\mathrm{CO}_{2}-$ UMA NOVA OPORTUNIDADE DE NEGÓCIOS PARA O BRASIL, Rio de Janeiro. Anais... Rio de Janeiro: CVRD, 1994. p. 125-145.

HIGUCHI, N.; SANTOS, J.; RIBEIRO, R. J.; MINETTE, L.; BIOT, Y. Biomassa da parte aérea da vegetação de floresta tropical úmida de terra-firme da Amazônia Brasileira. Acta Amazônica, Manaus, v. 28, p. 153-165, 1998.

HIGUCHI, N.; CHAMBERS, J.; SANTOS, J.; RIBEIRO, R. J.; PINTO, A. C. M.; SILVA, R. M.; TRIBUZY, E. S. Dinâmica e balanço do carbono da vegetação primária da Amazônia Central. Floresta, Curitiba, v. 34, n. 3, p. 295-304, set./dez., 2004.

HOUGHTON, R. A.; SCHLESINGER, W. H.; BROW, S.; RICHARDS, J. F. Carbon dioxide exchange between atmosphere and terrestrial ecosystems. In: TRABALKA, JOHN, R. (Ed.). Atmospheric carbon dioxide and the global carbon cycle. Washington, DC: U.S. Department of Energy, 1985. p. 114-140. (DOE/ER-0239).

HOUGHTON, R. A. As florestas e o ciclo de carbono global: armazenamento e emissões atuais. In: SEMINÁRIO EMISSÃO x SEQUESTRO DE $\mathrm{CO}_{2}$ - UMA NOVA OPORTUNIDADE DE NEGOCIOS PARA O BRASIL, Rio de Janeiro. Anais... Rio de Janeiro: CURD, 1994. p. 38-76.

HOUGHTON R. A. Land use change and carbon cycle. Global Change Biology, Oxford. Disponível em: $<$ http://www.ipcc.ch/>. Acesso em: 17/07/2005.

HU, H.; LIU, Y.; JIAO, Y. Estimation of the carbon storage of forest vegetation and carbon emission from forest fires in Heilongjiang Province, China. Journal of Forestry Research, China, v. 18, n.1, p.1722, 2007.

HUSCH, B.; MILLER, C. I.; BEERS, T. W. Forest mensuration. 3.ed. New York: JWiley \& Sons, 1982. $402 \mathrm{p}$.

IBAMA. Disponível em: <http://www.ibama.gov.br>. Acesso em: 07/07/2004.

IBAMA. GEO BRASIL 2002. Perspectivas do Meio Ambiente no Brasil. Brasília, DF, 2002, 440 p.

IPCC. INTERGOVERNMENTAL PANEL ON CLIMATE CHANGE. Climate change 2001: impacts, adaptation, and vulnerability: contribution of working group II to the third assessment report of the intergovernmental panel on climate change. MCCARTHY, J. J.; et al. (Eds.). Cambridge, UK, New York: Cambridge University Press, 2001

JENKINS, J. C.; CHOJNACKY, D. C.; HEATH, L. S.; BIRDSEY, R. A. National-scale biomass estimators for United States tree species. Forest Science, Lawrence, v. 49, p. 12-35, 2003.

JOHNSON, W. C., SHARPE, D. M. The ratio of total to merchantable forest biomass and its application to the global carbon budge. Canadian Journal of Forest research, Ottawa, v. 13, p. 372-383, 1983. 
KAUFFMAN, J. B.; CUMMINGS, D. L.; WARD, D. E. Relationships of fire, biomass and nutrient dynamics along vegetation gradient in the Brazilian cerrado. Journal of Ecology, London, v. 82, p. 519$531,1994$.

KAUPPI, P. E.; MIELIKAINEN, K.; KUSELA, K. Biomass and carbon budget of European forests, 1971 to 1990. Science, Washington, DC, n. 256, p. 70-74, 1992.

KETTERINGS, Q. M.; COE, R.; NOORDWIJK, M. van.; AMBAGAU, Y.; PALM, C. A. 2001. Reducing uncertainty in the use of allometric biomass equations for predicting above-ground tree biomass in mixed secondary forests. Forest Ecology and Management, Amsterdam, v. 146, p. 199-209, 2001.

$\mathrm{KOCH}, \mathrm{P}$. Estimates by species group and region in the USA of: I. Below-group root weight as a percentage of ovendry complete-tree weight; and II. In: CARBON content of tree portions: consulting report. [S.l.: s.n.], 1989. 23 p.

KOEHLER, H. S.; WATZLAWICK, L. F.; KIRCHNER, F. F. Fontes e níveis de erros nas estimativas do potencial de fixação de carbono. In: SANQUETA, C. R. et al. (Eds.). As florestas e o carbono. Curitiba: [S.1.: s.n.], 2002. p. 251-264.

LINDNER, M.; KARJALAINEN, T. Carbon inventory methods and carbon mitigation potentials of forests in Europe: a short review of recent progress. Europe Journal Forest Research. [S.1.], v. 126, p. 149-156, 2007.

MARTINELLI, L. A. et al. Incertezas associadas às estimativas de biomassa em florestas tropicais. SEMINÁRIO EMISSÃO X SEQÜESTRO DE CO2 - UMA NOVA OPORTUNIDADE DE NEGÓCIOS PARA O BRASIL, Rio De Janeiro. Anais... Rio de Janeiro: CURD, 1994, p. 197-221.

MARTINEZ-YRIZAR; SARUKHAN, A. J.; PEREZ-JIMENEZ, A.; RINCÓN, E.; MAASS, J. M.; SOLI-MAGALLANES, A.; CERVANTES, L. Aboveground phytomass of a tropical deciduous forest on the coast of Jalisco, Mexico. Journal of Tropical Ecology, Cambridge, v. 8, p. 87-96, 1992.

MONTGOMERY, D. C.; PECK, E. A. Introduction to linear regression analysis. 2.ed. New York: J. Wiley \& Sons, 1992. 527 p.

OGAWA, H.; KIRA, T. Primary Productivity of Japanese Forests. In: Productivity of terrestrial communities. Tokyo: [s.n.], 1977. v. 16. p. 15-21.

PARRESOL, B. R. Assessing tree and stand biomass: A review with examples and critical comparisons. Forest Science, Lawrence, v. 45, n. 4, p. i-r, 1999.

PÁSCOA, F.; MARTINS, F.; GONZÁLES, R. S.; JOAO, C. Estabelecimento simultâneo de equações de biomassa para o pinheiro bravo. In: SIMPÓSIO IBEROAMERICANO DE GESTIÓN Y ECONOMÍA FORESTAL, 2., Barcelona. p. i-f, 2004.

PELZ. D. R. Biomass studies in European overview. In: Estimating tree biomass regressions and their error. Broomall: USDA. Forest Service, 1987. p. 213-224. Proceedings of the work-shop on tree biomass regression functions and their contribution to the error of forest inventory estimates. (General Techical Report NE-117).

PEREIRA, J. C.; SCHUMACHER, M. V.; HOPPE, J. M. Produção de biomassa em um povoamento de Acacia mearnsii De Wild. no estado do Rio Grande do Sul. Revista Árvore, Viçosa, MG, v. 21, n. 4, p. 521-526, 1997.

PHILIP, M. S. Measuring trees and forests. 2.ed. New York: CAB International. 1994, 336 p.

REGAZZI, A. J.; LEITE, H. G. Análise de regressão: teoria e aplicações em manejo florestal. Viçosa, MG: UFV/DEF/SIF, 1993. 232 p. Apostila.

RUSSO, R. O. Mediciones de biomassa em sistemas agroflorestales. Turrialba: CATIE, 1983. 27 p.

SALATI, E. Emissão x seqüestro de $\mathrm{CO}_{2}$ - uma nova oportunidade de negócios para o Brasil. In: SEMINÁRIO EMISSÃO X SEQUESTRO DE $\mathrm{CO}_{2}$ - UMA NOVA OPORTUNIDADE DE NEGÓCIOS PARA O BRASIL, Rio de Janeiro. Anais... Rio de Janeiro: CVRD, p. 15-37, 1994. 
SALOMÃO, R. P.; NEPSTAD, D. C.; VIEIRA, I. C. G. Como a biomassa de florestas tropicais influi no efeito estufa? Ciência Hoje, São Paulo, v. 21, n. 123, p. 38-47, 1996.

SANQUETTA, C. R. et al. Ecuaciones de biomassa aérea y subterrânea em plantaciones de Pinus taeda em el sur del estado do Paraná, Brasil. In: SIPÓSIO INTERNACIONAL MEDICIÓN Y MONITOREO DE LA CAPTURA DE CARBONO EM ECOSISTEMAS FORESTALES, VALDIVIA: 1 CD-ROM. p. 1-11. (Documentos, 2001).

SANQUETTA, C. R. Métodos de determinação de biomassa florestal. In: SANQUETTA, C. R. et al. (Eds.). As florestas e o carbono. Curitiba: [s.n.], 2002, p. 119-140.

SANTOS, J. DOS. Análise de modelos de regressão para estimar a fitomassa da floresta tropical úmida de terra-firme da Amazônia brasileira. 121 f. Tese (Doutorado) - Universidade Federal de Viçosa, Viçosa, MG., 1996.

SCHNEIDER, P. R.; FINGER, C. A. G.; HOPPE, J. M.; GIACOMELLI SOBRINHO, V.; SCHNEIDER, P. S. P. Método de derivação do volume em biomassa e carbono: uma aplicação em Platanus $x$ acerifolia (AITON ) WILD. SIMPÓSIO LATINO-AMERICANO SOBRE MANEJO FLORESTAL. Santa Maria R. S., 3., Santa Maria. Anais... Santa Maria, RS: UFSM, 2004.

SCHNEIDER, P. R.; FINGER, C. A. G.; GIACOMELli SOBRINHO, V.; SCHNEIDER, P. S. P. Determinação indireta do estoque de biomassa e carbono em povoamentos de acácia-negra (Acácia mearnsii De Wild). Ciência Florestal, Santa Maria, RS, v. 15, n. 4, 2005.

SCHUMACHER, M. V.; HOPPE, J. M.; BARBIERI, S. Quantificação da biomassa e do conteúdo de nutrientes no corte raso de uma floresta de Araucaria angustifolia (Bert.) O. Ktze. na região de Quedas do Iguaçu-PR. Santa Maria, RS: UFSM, 2002. Relatório de pesquisa.

SCHÖNE, D.; SCHULTE, A. FORSTWIRTSCHAFT NACH Kyoto: Ansätze zur quantifizierung und betrieblichen Nutzung von Kohlenstoffsenken. Forstarchiv, Hannover, v. 70, p. 167-176, 1999.

SCOLFORO, J. R. S. Mensuração florestal: módulo 3: relações quantitativas, em volume, peso e a relação hipsométrica. Lavras: UFLA/FAEPE, 1997.

SCHROEDER, P. Carbon storage potencial of short rotation tropical tree plantations. Forest Ecology and Management, Amsterdam, v. 50, p. 31-41, 1992.

SEDJO, R. A. Temperature Forest ecosystem in the global carbon cycle. Ambio, Stockholm, v. 21, p. 274-277, 1992.

SHARP, D. D.; LIETH, H.; WHIGHAM, D. Assessment of regional productivity in North Carolina. In: LIETH, H,; WHITTAKER, R. H.. (Eds.). Primary...New York: Springer, p. 131-146, 1975.

SMITH, J. E.; HEATH, L. H.; WOODBURY, P. B. How to estimate forest carbon for large areas from inventory data. Journal of Forestry. Washington, DC, p. 25-31, Jul./Aug., 2004.

SOARES, C. P. B.; LEITE, H. G.; GORGENS, E. B. Equações para estimar o estoque de carbono no fuste de árvores individuais e em plantios comerciais de eucalipto. Revista Árvore, Viçosa, MG, v. 29, n. 5, p. i-f., oct. 2005.

SOMOGYI, Z.; CIENCIALA, E.; MÄKIPÄÄ, MUUKKONEN, P.; LEHTONEN A.; WEISS, P. Indirect methods of large forest biomass estimation. Europe Journal Forest Research, [S.1.], Feb., 2006.

SOUZA, C. L.; PONZONI, F. J. Avaliação de índices de vegetação e de bandas TM/LANDSAT para estimativa de volume de madeira em floresta implantada de Pinus spp. In: SIMPOSIO BRASILEIRO DE SENSORIAMENTO REMOTO, 9., Santos. Anais... Santos: INPE, 1998. 1 CD-ROM.

SPURR, S.H. Forest inventory. New York: Ronald, 1952, 476 p.

SPURR, S. H.; BARNES, B. V. Ecologia Forestal, México: [s.n.], 1986. 690 p.

TANIZAKI, K. F. Impactos do uso do solo no estoque e fluxo de carbono no domínio da Mata Atlântica: estudo de caso no estado do Rio de Janeiro. Tese (Doutorado) - Departamento de Geografia Ambiental, Universidade Federal Fluminense, Rio de Janeiro, 2000. 
TURNER, D. P.; HOEPPER, G. J.; HARMON, M. E.; LEE, J. J. A carbon budget for forest of the conterminous United States. Ecological Applications, Tempe, v. 5, p. 421-436, 1995.

UHL, C.; BUSCHBACHER, R.; SERRÃO, E. A. S. Abandoned pastures in Eastern Amazonia. I. Patterns of plant sucession. Journal of Ecology, Oxford, GB, v.76, p. 663-681, 1988.

VANCLAY, J. K. Modelling forest growth and yield: applications to mixed tropical forests. Wallingford: CAB International, 1994. $312 \mathrm{p}$.

VEIGA, R. A. de A. Uso de equações de volume em levantamentos florestais. In: SIMPÓSIO SOBRE INVENTÁRIO FLORESTAL, Piracicaba. Anais... Piracicaba: IPEF, 1981. p. 93-102.

VELOSO, H.P. Fitogeografia brasileira: classificação fisionômica da vegetação neotropical. Salvador: Projeto Radambrasil, 1982. 85 p. (Série Vegetação Salvador, n.1)

VOGEL, H. L. M.; SCHUMACHER, M. V.; TRÜBY, P. Quantificação da biomassa em uma Floresta Estacional Decidual em Itaara, R.S., Brasil. Ciência Florestal, Santa Maria, v. 16, n. 4, p. 419-425. 2006.

WATZLAWICK, L. F. et al. Ecuaciones de biomassa aérea em plantaciones de Araucaria angustifolia em el sur del estado do Paraná, Brasil. In: SIMPÓSIO INTERNACIONAL MEDICION Y MONITOREO DE LA CAPTURA DE CARBONO EM ECOSISTEMAS FORESTALES, VALDIVIA: 1 CD-ROM. p. 1-11. (Documentos, 2001).

WATZLAWICK, L. F.; KIRCHNER, F. F.; SANQUETTA, C. R.; SCHUMACHER, M. V. O papel do sensoriamento remoto nos estudos de carbono. In: SANQUETA, C. R. et al. (Eds.). As florestas e o carbono. Curitiba: [s.n.], 2002. p. 215-235.

WATZLAWICK, L. F. Estimativa de biomassa e carbono em Floresta Ombrófila Mista e plantações florestais a partir de dados de imagens do satélite IKONOS II. 120 f. Tese (Doutorado em Ciências Florestais) - Setor de Ciências Agrárias, Universidade Federal do Paraná. Curitiba, 2003.

WATZLAWICK, L. F.; BALBINOT, R.; SANQUETTA, C. R.; CALDEIRA, M. V. W. Teores de carbono em espécies da Floresta Ombrófila Mista. Fixação de carbono: atualidades, projetos e pesquisas. In: SANQUETTA, C. R.; BALBINOT, R.; ZILIOTTO, M. A. B. (Eds.). Fixação de carbono: atualidades, projetos e pesquisas. Curitiba: UFPR/Laboratório de Inventário Florestal, p. 95-109, 2004.

WENDLING, J. L. G. Modelos matemáticos de crescimento e produção em biomassa para árvores de Euterpe edulis Mart. Plantadas a céu aberto. 68 f. Dissertação (Mestrado em Ciências Florestais) Setor de Ciências Agrárias, Universidade Federal do Paraná, Curitiba, 1998.

WOOMER, P. L.; PALM, C. A. An approach to estimating carbon stocks in tropical forests and associated land uses. Commonwealth Forestry Review, Oxford, v. 77, n. 3, p. 181-190, 1998. 